\title{
SOBRE COMUNICAÇÃO E LINGUAGEM: UM OLHAR FILOSÓFICO
}

\author{
About communication and language: a philosophical look \\ Eleno Marques de Araújo - UNIFIMES/Brasil \\ José Humberto Rodrigues dos Anjos - UNIFIMES/UNIUBE/UNEMAT/Brasil
}

\begin{abstract}
RESUMO: Discutimos neste artigo a comunicação e a linguagem, a partir do ponto de vista filosófico e das reflexões de Aristóteles (1999), Heráclito (1999), Descartes (1999), Rousseau (1999), Hobbes (1999), Benjamim (2013), Eco (1997) e Chauí (2000). Sabe-se que a comunicação e a linguagem são atos sobretudo sociais, compostos de uma rede de signos e símbolos que exigem entre o emissor e o receptor da mensagem uma convenção pré-estabelecida. A ciência tem mostrado que estamos evoluindo, e assim como já se posicionou o francês Teilhard Chardin, criação e evolução não se excluem. Neste sentido, assumimos a linha de pensamento de Rousseau que supõe o começo da fala, mesmo que com articulações, gestos e sons idênticos aos dos animais: gralhas e macacos, ter surgido em ilhas. Isso é justificado pela proximidade da convivência, em razão de não poder distanciarem muito uns dos outros, e, sobretudo, como animais gregário, e ou político, segundo Aristóteles.
\end{abstract}

Palavras-chave: Signo. Símbolos. Comunicação. Linguagem.

ABSTRACT: We discuss in this article the communication and the language, from the philosophical point of view and the reflections of Aristotle (1999), Heráclito (1999), Descartes (1999), Rousseau (1999), Hobbes (1999), Benjamim ), Eco (1997) and Chauí (2000). It is known that communication and language are mainly social acts, composed of a network of signs and symbols that require between the sender and the receiver of the message a pre-established convention. The science has shown that we are evolving, and just as Frenchman Teilhard Chardin has already posed, creation and evolution are not excluded. In this sense, we assume the line of thought of Rousseau that supposes the beginning of speech, even if with articulations, gestures and sounds identical to those of animals: rooks and monkeys, have arisen in islands. This is justified by the proximity of the coexistence, because is not being able to distance much from each other, and, above all things, as animal gregarious, and or political, according to Aristotle.

Keywords: Sign. Symbols. Communication. Language.

\section{INTRODUÇÃO}

Educação, Psicologia e Interfaces, Volume 2, Número 2, p. 97-110, Maio/Agosto, 2018.

ISSN: 2594-5343. DOI: https://doi.org/10.37444/issn-2594-5343.v2i2.95 
Antes de iniciar a discussão sobre uma temática tão ampla, destaca-se de antemão que o assunto é amplo e requer necessariamente um cuidado especial, uma vez que o lócus referencial será a partir do ponto de vista de um olhar filosófico, e não exclusivamente linguístico. Neste sentido, "sendo o discurso argumentativo um assunto legitimamente filosófico, e tendo em vista a vocação da Filosofia para o universal, as condições transcendentais de possibilidade do próprio discurso" (SISCAR, 2004, p. 180) deixaremos aqui nossa contribuição sobre essa delimitação de um tema, que como já dissemos é amplo e de interpretações inesgotáveis.

Elucubrando um pouco mais, percebemos que a abordagem incluirá elementos que não menos profundos ou importantes que a própria linguística, ajudarão na reflexão filosófica sobre a linguagem. Neste sentido, buscar-se-á apoio em escritos de filósofos sobre a Filosofia da Linguagem.

Evocamos, de início, o pensamento de Siscar (2004, p. 190) ao sustentar o dever e a necessidade de que a linguagem precisa "ser enfrentada pela Filosofia, pois ela é pressuposto da problemática fundamental da construção científica de conceitos e teorias e dos próprios enunciados filosóficos, isto é, da formulação com sentido e válida intersubjetivamente do conhecimento enquanto tal".

Para tanto, primeiro faz-se necessário estabelecer o que entendemos pelos termos comunicação e linguagem. Embora, todos possam ter as noções básicas do que encerram estes dois conceitos, escrever sobre eles requer ir à fonte dada pelos verbetes. Houaiss (2001, p. 781) preleciona que a comunicação é a

\begin{abstract}
ação de transmitir uma mensagem e, eventualmente, receber outra mensagem como resposta; processo que envolve a transmissão e a recepção de mensagens entre uma fonte emissora e um destinatário receptor, no qual as informações, transmitidas por intermédio de recursos físicos (fala, audição, visão etc) ou de aparelhos e dispositivos técnicos, são codificadas na fonte e decodificadas no destino com o uso de sistemas convencionados de signos ou símbolos sonoros, escritos, iconográficos, gestuais etc; [...].
\end{abstract}

Conforme a afirmação acima, transparece de forma implícita a presença dos sujeitos que comunicam. Alguém que emite uma mensagem a outro que em algum lugar a recebe e a decodifica, isto é, que a interpreta ou que simplesmente, a compreende,

Educação, Psicologia e Interfaces, Volume 2, Número 2, p. 97-110, Maio/Agosto, 2018.

ISSN: 2594-5343. DOI: https://doi.org/10.37444/issn-2594-5343.v2i2.95 
porque já lhe são familiares todos os códigos enviados, não importando o tipo de recurso/estilo que o emissor escolheu: fala, escrita, gesto etc.

Na mesma linha de definição de Houaiss está a afirmação de Ferreira (1986, p. 443) que vê a comunicação como um "ato ou efeito de emitir, transmitir e receber mensagens por meio de métodos e ou processos convencionados, quer através da linguagem falada ou escrita, quer de outros sinais, signos ou símbolos, quer de aparelhamento técnico especializado, sonoro e ou visual".

Se comunicação é tudo o que se definiu acima, resta-nos ainda acordar sobre o que compreendemos por linguagem. Assim afirma Ferreira, (1986, p. 1035) que a "linguagem é o uso da palavra articulada ou escrita como meio de expressão e de comunicação entre pessoas". Portanto, podemos perceber que entre comunicação e linguagem existem relações diretas, mas na especificidade de cada uma, existem, também, certos distanciamentos.

Em termos lógicos, a comunicação é universal e a linguagem é particular. Pelo que se afirmou até aqui é possível concluir que comunicação é o ato de usar de certos recursos - inclusive a linguagem - para expressar aquilo em que uma pessoa pensa, sente, ou de que necessita, por exemplo.

\section{FILOSOSIA E LINGUAGEM}

Pela História da Filosofia constata-se facilmente que o assunto abordado neste artigo sempre recebeu contribuições de pensadores indo desde Platão até os atuais como Karl-Otto Apel. Por conseguinte, "Platão se ocupou da linguagem no diálogo Crátilo, texto apontoado como o primeiro esboço de uma Filosofia da linguagem. A propósito da discussão sobre a exatidão dos nomes e da formação das palavras, ele acaba oferecendo subsídios para uma análise reflexiva da linguagem” (SISCAR, 2004, p. 185).

Mais recentemente Benjamin (2013, p. 55) assevera que "a essência linguística do homem está no fato de ele nomear as coisas. A quem se comunica a lâmpada? A quem, a montanha? E a raposa? - Aqui a resposta é: ao homem". O autor afirma a existência de uma linguagem por meio do nome que o ser humano atribui as coisas ou entes. Dessa forma continua a afirmar que 
Assim, como parte do legado da linguagem humana, o nome garante que a língua é pura e simplesmente a essência espiritual do homem; e é somente por isso que o homem é, entre todos os seres dotados de espírito, o único cuja essência espiritual é plenamente comunicável. É isso que fundamenta a diferença entre a linguagem humana e a linguagem das coisas (BENJAMIN, 2013, p. 56).

As coisas comunicam ao ser humano aquilo que para ele significam por meio do nome atribuído a cada uma delas por ele mesmo. Assim, a lâmpada comunica sua luz se está cumprindo sua linguagem de ser lâmpada. Uma montanha de per si é majestosa e impõe através da linguagem comunicativa ao humano esta majestade, poderá comunicar também a diferença entre ela e um vale, ou ainda uma chapada. O mesmo vale para a raposa que comunica ao homem sua existência raposesca que é absolutamente distinta de uma ave, por exemplo.

Benjamin evoca o momento criacionista da tradição judaico cristã, narrado nos textos sagrados, para assegura a importância do nome das coisas com o processo de comunicação e de conhecimento. Há, segundo ele, uma relação intrínseca e necessária neste evento:

A relação absoluta do nome com o conhecimento só existe em Deus, só nele o nome, porque é intimamente idêntico à palavra criadora, é o puro meio do conhecimento. Isso quer dizer: Deus tornou as coisas cognoscíveis ao lhes dar nomes. Mas o homem só nomeia as coisas na medida em que as conhece (BENJAMIN, 2013, p. 61).

Em sintonia de pensamento com Benjamin, Hobbes (1999, p. 43) remete a Deus a autoria da linguagem: "o primeiro autor da linguagem foi o próprio Deus, que ensinou a Adão a maneira de designar aquelas criaturas que colocava à sua vista, pois as Escrituras nada mais dizem a respeito". Neste interim Comenius, (2001, p. 22) assegura que o homem "é criatura racional quer dizer que observa, dá o nome e se apercebe de todas as coisas, isto é, que pode conhecer e dar um nome a todas as coisas deste mundo e entendêlas, como é evidente (Gênesis, 2, 19)".

As coisas criadas comunicam ao humano uma linguagem muda. Essa linguagem é interpretada pelo homem que a decodifica e nomeia a existencialidade das coisas, pois "pela palavra o homem está ligado à linguagem das coisas. A palavra humana é o nome das coisas" (BENJAMIN, 2013, p. 63). Entretanto, o "conhecimento da coisa não é, contudo, uma criação espontânea, ele não acontece a partir da linguagem de maneira 
absolutamente ilimitada e infinita, como ocorre na Criação; o nome que o homem atribui à coisa repousa sobre a maneira como ela se comunica a ele" (BENJAMIN, 2013, p. 64). Finalmente sustenta Benjamin, (2013, p. 64) que "traduzir a linguagem das coisas para a linguagem do homem não consiste apenas em traduzir o que é mudo para o que é sonoro, mas em traduzir aquilo que não tem nome em nome". Assim sendo, o nome comunica a cognoscidade existencial da coisa o ente.

Por outro lado, na Alegoria da Caverna, no livro sétimo de A República, Platão expõe sua teoria dos dois mundos: sensível e suprassensível. O mundo das Formas ou das Ideias, conforme a descrição feita pelo filósofo revela uma ambiguidade entre as duas realidades. O mundo sensível é imperfeito e não leva à verdade das coisas. Dessa forma, Platão assegurava "que a linguagem não é fonte segura para o conhecimento da verdade, pois a essência das coisas traduz-se na sua ideia, que é definida e estável, enquanto sua representação linguística é apenas um pálido reflexo do conceito” (SISCAR, 2004, p. $185)$.

Ainda no texto de Crátilo, segundo Siscar (2004, p. 186), "Platão busca demonstrar, ao longo de todo o diálogo, que deve haver uma relação de coerência entre a palavra (signo) e o seu sentido (significado)". Por outro lado, Benjamin (2013, p. 63) garante que "não vigora mais a concepção burguesa da língua segundo a qual a palavra estaria relacionada à coisa de modo casual e que ela seria um signo das coisas (ou de seu conhecimento), estabelecido por uma convenção qualquer. A linguagem não fornece jamais meros signos". Porque é resultado da comunicação entre as coisas e o homem que lhe atribuem significados.

Segundo Chauí (2000, p. 173) "no diálogo Fedro, Platão dizia que a linguagem é um pharmakon. Esta palavra grega, que em português se traduz por poção, possui três sentidos principais: remédio, veneno e cosmético". Na sequência a autora explica que

Platão considerava que a linguagem pode ser um medicamento ou um remédio para o conhecimento, pois, pelo diálogo e pela comunicação, conseguimos descobrir nossa ignorância e aprender com os outros. Pode, porém, ser um veneno quando, pela sedução das palavras, nos faz aceitar, fascinados, o que vimos ou lemos, sem que indaguemos se tais palavras são verdadeiras ou falsas. Enfim, a linguagem pode ser cosmético, maquiagem ou máscara para dissimular ou ocultar a verdade sob as palavras. A linguagem pode ser conhecimento-comunicação, mas também pode ser encantamento-sedução (CHAUÍ, 2000, p. 173). 
A tríplice função representativa da linguagem, por meio de pharmakon evidencia as ocorrências cotidianas da vida de muitas pessoas que acreditam no poder da palavra. Como remédio as palavras ganham força e poder existencial de curar ou transformar a realidade desde tempos antigos. No Novo Testamento cristão, a palavra de Jesus de Nazaré curou muitas pessoas, como é o caso da filha de Jairo que já estava morta, proferindo as palavras "Talita Cum”, que significam: "menina levanta e anda”. A palavra neste contexto, curou de morte a menina. Neste mesmo interim a chamada ressurreição de Lazaro, no Evangelho de São João pode exemplificar o poder da palavra. Ao pronunciar-se chamando Lazaro à vida, ele que já estava morto a quatro dias, e até cheira mau não é somente ir de um lugar a outro, mas é sair da morte e voltar a viver, isto é, ser curado da morte.

A segunda dimensão de pharmakon é veneno e está evidentemente em oposição a primeira. Veneno sempre serviu para matar algum ente que esteja vivo, combater a vida. Toda palavra pronunciada de má fé, mentindo e enganando as outras pessoas estará sempre carregada de veneno, porque objetivam tornar um contexto contrário ao que ele é. Por exemplo as palavras ditas pelos acusadores de Sócrates na obra Apologia de Sócrates estavam carregadas de veneno, tanto que levaram-no ao copo de Cicuta, retirando-lhe a vida.

A terceira e última representação de pharmakon é cosmético. Esta terceira dimensão tem uma função intermediária, ou seja, está entre remédio e veneno. Seu uso correto não mata, mas também não cura. Será sempre um paliativo. A realidade do ente que usa cosmético será quase sempre a mesma. Quando bem compreendido o sentido figurado tem a função de velar, encobrir algo, esconder a situação de morte em que a realidade nua e crua está evidenciando.

Por exemplo, uma mulher já avançada na idade mostra os sinais de envelhecimento - rugas nas faces e cabelos brancos. O cosmético tem a função de afastar estes sinais, deixando-a mais jovial e até mais bela. Entretanto, ao retirar o pharmakon seus cabelos estão brancos e as rugas permanecem em sua face. Esta é a dimensão de veneno embutido no cosmético que maquia a realidade, mas só transforma na aparência, a verdade é diferente. $O$ reverso deste contexto deixa aflorar a segunda função do cosmético: a mulher ficou mais jovial, está mais bela, encara a vida com mais disposição dá o animus, e está é a função do remédio, animar para a vida, curar. 
A função linguística de pharmakon, enquanto representação, leva por intuição, à conclusão de que comunicação e linguagem são atos sociais, uma vez que por meio da palavra/linguagem vivifica, mortifica ou maquia a realidade. Não é necessário devanear aqui sobre o que é uma sociedade. Por hora é suficiente a seguinte definição, mesmo que elementar: uma sociedade é caracterizada pela união de alguns indivíduos visando uma finalidade qual quer que seja. Aristóteles (1999, p. 146), na obra A Política: assegura que: "é evidente que o homem é um animal mais político do que as abelhas ou qualquer outro ser gregário". Escrevendo sobre este assunto Chauí (2000, p. 172), diz que:

Aristóteles afirma que somente o homem é um 'animal político', isto é, social e cívico, porque somente ele é dotado de linguagem. Os outros animais, escreve Aristóteles, possuem voz (phone) e com ela exprimem dor e prazer, mas o homem possui a palavra $(\log o s)$ e, com ela, exprime o bom e o mau, o justo e o injusto.

Ser capaz de exprimir o bom e o mau, o justo e o injusto é fazer uso da linguagem de forma comunicativa e racional para emitir juízos de valores. Bom e mau são conceitos culturais, e, portanto, dependem da comunidade que valora algo bom ou mau. Nietsche discute estes conceitos em sua obra Genealogia da Moral demonstrando que sempre há uma sociedade subjacente na culturalidade negativa destes conceitos. Aquela sociedade que introjetou para si mesma as dimensões positiva e negativa destes conceitos, repassa para as gerações futuras seus próprios elementos culturais. É necessário ressaltar que o renomado filósofo acrescenta outros dois conceitos: Bom e Ruim, bem e mau. Visivelmente constata-se a logicidade estruturada de forma cultural: bom está para ruim, assim como bem está para mau. Entretanto, Nietsche demonstra que ser bom é sempre para uma parte da sociedade e nunca para a totalidade, assim como ser ruim também nunca atinge a todos os elementos que a compõe. O reverso vale para bem e mau.

Evidenciando de forma exemplar a reflexão nietcheana toma-se aqui uma sociedade governada por um regime autoritário, como é o caso da China, ou de outros países similares. O termo bom é aplicado para o cidadão que não questiona o regime, que é subalterno, que deixa ser governado pelas autoridades ditatoriais sem a participação popular de forma democrática. Para exemplificar o conceito ruim, também, no contexto político, o atual cenário brasileiro é ideal. A 'Era Temer' está tratando de realinhar a economia brasileira para a produtividade e construir a chamada "ponte para o futuro". 
Para isto, cortam-se todos os direitos trabalhistas conseguidos a dura lutas históricas, sendo assim, todo cidadão que apresentar-se para protestar contra esse novo desenho é ruim.

O mesmo se pode afirma para os termos justo e injusto. Sempre do ponto de vista de quem sofre uma punição: pena ou castigo, este sujeito julga ou valora ter sido injustiçado já afirmava Santo Agostinho em O Livre Arbítrio. Porém, a outra parte envolvida sempre sentirá que recebeu a seu favor a justiça, isto é, significa para aquele 'eu' do indivíduo a afirmação de que ele é justo. Infere-se dessa visão agostiniana que a linguagem também é cultural, uma vez que os termos utilizados na comunicação então imbricados de elementos culturais e não asseguram nenhuma evidência, mas sempre é necessário analisar o contexto em que o termo está sendo conotado.

\section{BUSCANDO O ARCHÉ DA LINGUAGEM}

Conforme Rousseau (1999, p. 87) "o primeiro sentimento do homem foi o de sua existência, sua primeira preocupação a de sua conservação”. Portanto, se o ser humano é gregário, vive em bando e, neste caso, capaz de ser sociável, dado a certas necessidades comuns ao gênero, a primeira destas necessidades é a de conservação: precisa de alimentos, proteção contra os predadores e, sobretudo, a cópula para a procriação.

Esta descrição, embora, resumida, é um retrato de uma sociedade primitiva. Tudo isso se dá, quase que, de forma instintiva, assim como se passa até hoje com outros animais gregários que também se reúnem adotando uma forma de vida gregária para a conservação da espécie, como entre as formigas, os cupins, as abelhas, os macacos, os leões, os lobos em certas regiões, e as hienas.

Como os humanos não nasceram prontos e acabados, mas foram aperfeiçoados pela natureza, é bom ter presente o que afirma a pesquisa sobre a origem das desigualdades entre os homens, realizada por Rousseau (1999, p. 90), que afirma que "a linguagem no início era como a das gralhas ou dos macacos que se reúnem quase do mesmo modo. Gritos inarticulados, muitos gestos e alguns ruídos imitativos compuseram durante muito tempo a língua universal". Aqueles animais não evoluíram e mantêm-se basicamente os mesmos gritos e gestos de geração em geração, na sucessão dos séculos, entretanto, a espécie humana foi se descobrindo racionalmente, e como tal, aperfeiçoando 
o processo de comunicação. Desta forma novos gritos, gestos, e símbolos vão sendo inventados e incorporados no processo de comunicação.

Sem a racionalidade nada seria diferente com os humanos. Mas, com ela e a partir dela, entram em cena outros elementos importantes. O primeiro deles é o de identidade do sujeito, isto é, a individuação. A pessoa, conforme afirma o professor José Avelino da Silva $^{1}$ (2009) passa a ter consciência do seu eu individual, frente ao outro que possibilita a identificação do eu. Nunca teria consciência do meu eu individualizado, se não existisse um tu, diante de mim, que se coloca como um paradigma para o meu eu. É olhando para as diferenças individuais do tu que se coloca como absolutamente distinto frente a mim, que sou capaz de perceber minha individualidade.

O tu paradigmático, anteposto a mim, não tem pêlo nas faces e no tórax, seus mamilos são avantajados, você sangra a cada ciclo lunar, depois de copular sua barriga vai esticando para frente e depois de algum tempo nasce uma cria. Diante de seu ser, o tu, diferente de meu eu, consigo identificar-me como diferente. Tenho pêlo nas faces e no tórax, meus mamilos não são grandes, não tenho sangramentos a cada ciclo lunar, depois da cópula nada acontece com minha barriga, isto é, não estica e não nascerá nenhuma cria. A conclusão é óbvia: eu não sou você, isto é, não sou igual a você. Tu é biologicamente ${ }^{2}$ diferente do meu eu.

Com o tu, que não sou eu, estabeleço segundo Aristóteles uma relação gregária e familiar, isto é, de parceria de vida. Mas não devemos de início pensar que o ser humano podia expressar suas intenções assim como são expressadas hoje. A linguagem é fruto de uma construção social. O que é natural no corpo da pessoa, sãos os componentes biológicos da aparelhagem que possibilitam que o humano desenvolva o processo de comunicação. Dessa forma, Chauí (2000, p. 173), assegura que "a linguagem como capacidade de expressão dos seres humanos é natural, isto é, os humanos nascem com uma aparelhagem física, anatômica, nervosa e cerebral que lhes permite expressarem-se pela palavra". Entretanto, para isso, a pessoa precisa necessariamente ser socializada no

\footnotetext{
${ }^{1} \mathrm{O}$ professor Avelino é membro fundador da International Association for Greek Philosophy. Essa associação reúne em congressos todos os anos em uma cidade da Grécia.

${ }^{2}$ Como não é objetivo deste ensaio discutir a questão de gênero optamos pelo termo biologicamente diferente, evitando os conceitos feminino e masculino, reconhecendo que existe toda uma discussão já elaborada sustentando que também estes termos são construídos socialmente.
} 
interior de uma comunidade que desenvolveu uma linguagem específica. Sendo assim, a filósofa continua a afirma: "as línguas são convencionais, isto é, surgem de condições históricas, geográficas, econômicas e políticas determinadas, ou, em outros termos, são fatos culturais" (CHAUÍ, 2000, p. 176).

Segundo Rousseau, (1999, p. 89), o processo de individuação ocorre, portanto, pelo olhar, e sem dúvidas este olhar se dá a partir do outro, conforme já foi dito acima. A individuação leva necessariamente a outros avanços, como por exemplo, "a construção dos casebres determinou o estabelecimento e a distinção das famílias e introduziu uma espécie de propriedade da qual nasceram talvez brigas e combates" (ROUSSEAU, 1999, p. 90).

É pressuposto que "os mais fortes possivelmente foram os primeiros a fazer habitações que se sentiam capazes de defender, é de crer que os fracos acharam mais rápido e seguro imitá-los do que tentar desalojá-los” (ROUSSEAU, 1999, p. 90). Dessa forma, nos assegura Rousseau (1999, p. 90) "os primeiros progressos do coração resultaram de uma situação nova que reunia numa habitação comum os maridos e as mulheres, os pais e os filhos". Neste sentido, acrescenta ainda o genebrino: "o hábito de viver junto fez com que nascessem os mais doces sentimentos que são conhecidos do homem, como o amor conjugal e o amor paterno [...] Cada família tornou-se uma pequena sociedade, ainda mais unida por serem a afeição recíproca e a liberdade os únicos liames" (ROUSSEAU, 1999, p. 90-1).

Dada a enorme extensão continental, o que favorecia a dispersão das pessoas, levou Rousseau (1999, p. 91) a concluir que "depois de suas primeiras tentativas de navegação, alguns insulares tenham trazido até nós o uso da palavra e é pelo menos bastante verossímil que a sociedade e as línguas tenham nascido nas ilhas e aí se aperfeiçoado antes de serem conhecidas no continente". A razão disso é que a estreiteza e os limites impostos pela convivência diária ajudaram na compreensão e assimilação de gestos, sons e símbolos, o que permitiu o aperfeiçoamento da comunicação e consequentemente da linguagem. Assim, "eis, pois, todas as nossas faculdades desenvolvidas, a memória e a imaginação em ação, o amor-próprio interessado, a razão em atividade, alcançando o espírito quase que o termo da perfectibilidade de que é suscetível” (ROUSSEAU, 1999, p. 97). 
Heráclito de Éfeso (1999, p. 89), um eminente pensador Pré-Socrático, da Ásia Menor escreveu: "homens que não sabem ouvir nem falar". Certamente que não sabem ouvir o que os outros falam e nem sabem comunicar os seus próprios pensamentos. Em outras palavras, essa reflexão filosófica se repete na dúvida hiperbólica de René Descartes. Este filósofo, ao inaugurar o pensamento moderno, afirma que só podemos conhecer verdadeiramente as coisas via as formas matemáticas. Embora Zenão (1999) seja o primeiro a provar que a existência não acontece, também por formas matemáticas, via a negação do movimento, pois qualquer distância entre as grandezas A e B teria que ser dividida em uma metade, e esta novamente em outra metade e assim sucessivamente ad infinitum. Logo, o movimento não existe, nem a flecha jamais poderia atingir o calcanhar de Aquiles, pois, também este deveria ocupar um lugar e também o lugar não existe, e a própria existencialidade de Aquiles acaba por ser negada.

Retornando ao pensamento cartesiano, o caminho encontrado por Descartes para comunicar suas investigações sobre a verdade no avanço das ciências foi o da dúvida. Começou por duvidar de tudo, inclusive de sua existência pessoal. Muitos entes existem, mas, não têm consciência de suas existências. Sua primeira certeza foi a do pensamento. A segunda foi a de sua existência "penso logo, existo". Nesta grande verdade cartesiana do 'cogito ergo sum' originam as expressões: res cogitans e res extensa, isto é, a coisa pensante e a coisa pensada. Portanto, uma coisa é o ente que pensa, outra o objeto pensado.

Conforme afirmamos acima, pode-se utilizar de diferentes recursos para a nossa comunicação. O desdobramento do cogito cartesiano implica que sou um ser pensante, que minha existência é real e concreta e que posso comunicar meus pensamentos a outros que também pensam, que também existem e logo, que são capazes de comunicação.

Evocando novamente Heráclito (1999, p. 93), este diz que

Estão iludidos os homens quanto ao conhecimento das coisas visíveis, mais ou menos como Homero, que foi mais sábio que todos os helenos. Pois enganaram-no meninos que matando piolhos lhe disseram: o que vimos e pegamos é o que largamos, e o que não vimos nem pegamos é o que trazemos conosco (Fragmento 56).

Vemos neste fragmento de Heráclito o fundamento do devir e consequentemente a origem da dialética. O que vimos e pegamos é nossa existência, que é deixada para trás, 
pois não nos pertence mais, pois foi largada, esquecida. O que nem vimos, nem pegamos, mas trazemos conosco é nosso vir-a-ser, aberto ao processo dialético de nossa existência pensante, comunicativa e aberta com tudo o que representa a novidade ainda não conhecida e vivida por cada um.

Eco (1997) ao afirmar que para haver comunicação é absolutamente necessário um encadeamento composto de fonte, emissor, canal, mensagem e destinatário. Identificamos estes elementos da seguinte forma: fonte e emissor neste caso se confundem com minha pessoa, ao mesmo tempo sou a fonte dessa comunicação e também o emissor da mesma; o canal é toda a aparelhagem de som, os microfones, os fios, as caixas; a mensagem é todo o conteúdo de minha fala, ou seja, o conjunto de signos articulados que são pronunciados por mim; e finalmente o destinatário é cada um dos outros que nos ouvem.

\section{CONSIDERAÇÕES FINAIS}

Como comunicar nem sempre é dizer, devemos ainda verificar se aqui houve uma comunicação. Se ela procedeu, temos a certeza de que a mensagem foi decodificada em seu destino. Para acontecer a decodificação, é preciso que haja um acordo prévio entre o emissor e destinatário quanto aos signos utilizados na mensagem. Logo, no processo de individuação ao ter afirmado que o meu eu é identificado diante de um tu que se coloca como distinto de mim, como vimos cada um é de um sexo distinto do outro, mas não é só isso. Possuir sexo diferente um do outro não os distingue do gênero humano, mas os tornam seres comunicadores de uma linguagem, que, se socializados na mesma comunidade de vida, utilizarão para isso, os mesmos signos. Como afirma Siscar (2004, p. 180), o signo tem uma função pragmática "que aponta para a intersubjetividade da razão humana, ignorada historicamente nas grandes correntes filosóficas do Ocidente, cujos proferimentos permaneciam nos aspectos sintático e semântico da linguagem”. Este tipo de análise esvazia a linguagem de seu verdadeiro sentido.

\section{REFERÊNCIAS BIBLIOGRÁFICAS}

BENJAMIN, Walter. Escritos Sobre Mito e Linguagem. Tradução de Susana Kampff Lages e Ernani Chaves. 2. ed. São Paulo: Duas Cidades; 34, 2013.

CHAUI, Marilena. Convite à Filosofia. São Paulo: Ática, 2000. 
COMENIUS, João Amos. Didática Magna. Tradução de Joaquim Ferreira Gomes. Versão para eBook. eBooksBrasil.com: Copyright, 2001.

ECO, Umberto. O Signo. 5. ed. Lisboa: Presença, 1997.

HOUAISS, Antônio. Dicionário Houaiss da Língua Portuguesa. Rio de Janeiro: objetiva, 2001.

FERREIRA, Aurélio B. de Holanda. Novo Dicionário da Língua Portuguesa. 2. ed. Rio de Janeiro: Nova Fronteira, 1986.

HERÁClitO. Os Pré-Socráticos. Tradução de José Cavalcante de Souza. São Paulo, Nova Cultura, 1999.

HOBBES, Tomas. O Leviatã. Tradução de João Paulo Monteiro e Maria Beatriz Nizza da Silva. São Paulo, Nova Cultura, 1999.

NIETZSCHE, Freidrich. Genealogia da moral. Tradução de Rubens Rodrigues Torres Filho. São Paulo. Nova Cultural, 1999.

PLATÃO. A República. Tradução de Enrico Corvisieri. São Paulo: Nova Cultural, 1999.

ROUSSEAU, Jean-Jacques. Discurso Sobre a Origem e os Fundamentos da Desigualdade Entre os Homens. Trad. Lourdes S. Machado. v. 2. São Paulo: Nova Cultural, 1999.

ROUSSEAU, Jean-Jaques. Do Contrato Social. Ensaio Sobre a Origem das Línguas. Vol. 1. Tradução de Lourdes Santos Machado. São Paulo: Nova Cultural, 1999.

SANTO AGOSTINHO. O Livre Arbítrio. Tradução de Nair de Assis Oliveira. São Paulo, Paulus, 1995.

SILVA, J. C. Avelino. O Sagrado e a Individualidade. Goiânia: UCG, 2009.

SISCAR, Crisnanda Pane. DIREITO E MÍDIA. In. BITTAR, Eduardo Carlos Bianca; Soares, Fabiana de Menezes (Orgs). TEMAS DE FILOSOFIA DO DIREITO: novos cenários, velhas questões. Baruerí: Manole, 2004. p. 179-203.

\section{Credenciais dos autores}

ARAÚJO, Eleno Marques de. Licenciado em Filosofia pela UFG. Bacharel em Teologia, Mestre e Doutor em Ciências da Religião pela PCUGGOIÁS. É professor e diretor de pesquisa na Unifimes. É pesquisador do GP-NEPEM cnpq e Membro do GEFOPI-UEG. E-MAIL: profelenoaraujo@outlook.com

ANJOS, José Humberto Rodrigues dos. Doutorando em Educação pela Universidade de Uberaba- UNIUBE, mestre em Estudos da Linguagem, pela Universidade Federal de Goiás - UFG, graduado em Letras, Português/Inglês pela Universidade Estadual de Goiás - UEG e em Pedagogia pela Faculdade Mantenense dos Vales Gerais - Intervale. Atualmente é professor Adjunto no Centro Universitário de Mineiros - Unifimes e na Universidade do Estado do Mato Grosso - UNEMAT. 
Endereço para correspondência: Eleno Marques de Araújo. Unifimes -Centro Universitário de Mineiros, Rua 22, s/n - Bairro Aeroporto, Mineiros- GO, CEP 75830000 Brasil. E-mail: profelenoaraujo@outlook.com

Como citar este artigo (Formato ABNT): ARAÚJO, Eleno Marques de; ANJOS, José Humberto Rodrigues dos. Sobre comunicação e linguagem: um olhar filosófico. Educação, Psicologia e Interfaces, v. 2, n. 2, p.97-110, 2018. DOI: https://doi.org/10.37444/issn-2594-5343.v2i2.95

Recebido: $25 / 04 / 2018$.

Aceito: 20/05/2018. 